\title{
Mass transfer coefficients for polycyclic aromatic hydrocarbons (PAHs) to the water surface sampler: comparison to modeled results
}

\author{
Mustafa Odabasi ${ }^{\mathrm{a}, *}$, Aysun Sofuoglu ${ }^{\mathrm{b}}$, Thomas M. Holsen ${ }^{\mathrm{c}}$ \\ a Department of Environmental Engineering, Faculty of Engineering, Dokuz Eylul University, Kaynaklar Campus, 35160 Buca, Izmir, Turkey \\ ${ }^{\mathrm{b}}$ Izmir Institute of Technology, Alsancak, Izmir, Turkey \\ ${ }^{\mathrm{c}}$ Department of Civil and Environmental Engineering, Box 5710, Clarkson University, Potsdam NY 13699, USA
}

Received 24 February 2000; accepted 24 August 2000

\begin{abstract}
A sampling program was conducted between June and October 1995 in Chicago, IL using a modified water surface sampler (WSS) and dry deposition plates to measure the particulate dry deposition and gas exchange of PAHs. Oxygen transfer experiments were also conducted to evaluate the collection properties of the WSS for gas-phase compounds. Gas-phase fluxes were determined by subtracting the dry deposition plate fluxes (particulate) from WSS fluxes (particulate + gas). These fluxes were divided by concurrently measured ambient concentrations to obtain overall gas phase mass transfer coefficients. Two different two-film models, one developed based on experiments performed with the WSS and, one previously published, were compared to these results. Experimentally determined average gas phase overall mass transfer coefficient $\left(K_{\mathrm{g}}\right)$ for seven PAHs was $0.74 \pm 0.52 \mathrm{~cm} \mathrm{~s}^{-1}$. Experimental $K_{\mathrm{g}}$ values agreed well with those predicted by the model developed for WSS. The values predicted by previously proposed models were within a factor of 3 of the experimental ones. (C) 2001 Elsevier Science Ltd. All rights reserved.
\end{abstract}

Keywords: PAHs; Air-water exchange; Water surface sampler; Mass transfer coefficient

\section{Introduction}

There has been considerable investigation of the magnitude and direction of gas exchange of semivolatile organic compounds (SOCs) in recent years. Paired or unpaired air and water concentration measurements in conjunction with the two-film model (Schwarzenbach et al., 1993) have been commonly used to estimate atmospheric loading of SOCs to water bodies (Baker and Eisenreich, 1990; Hornbuckle et al., 1994; Hoff et al., 1996; Pirrone et al., 1995; Erickson, 1987; Wanninkhof, 1992; Gustafson and Dickhut, 1997; McConnell et al., 1997). The mass balance approach has also been used to make estimates of air-water gas exchange (McVeety and Hites, 1988).

\footnotetext{
* Corresponding author. Fax: + 90-232-453-0922.

E-mail address: mustafa.odabasi@deu.edu.tr (M. Odabasi).
}

According to the two-film model, mass transfer is limited by the rate of molecular diffusion through thin films of air and water on either side of the surface (Schwarzenbach et al., 1993). The net flux $\left(F_{\mathrm{g}}, \mathrm{ng} \mathrm{m}^{-2} \mathrm{~d}^{-1}\right)$ is driven by the fugacity difference between air and surface water.

$F_{\mathrm{g}}=K_{\mathrm{g}}\left(C_{\mathrm{g}}-C_{w} H / R T\right)$,

where $C_{\mathrm{w}}$ and $C_{\mathrm{g}}$ are the water and air concentrations of SOCs $\left(\mathrm{ng} \mathrm{m}^{-3}\right), H$ is the Henry's law constant $\left(L \mathrm{~atm} \mathrm{~mol}{ }^{-1}\right), \quad R$ is the universal gas constant $\left(0.082051 \mathrm{~atm} \mathrm{~mol}^{-1} \mathrm{~K}^{-1}\right)$, and $T$ is temperature at the air-water interface $(\mathrm{K})$. The gas-phase overall mass transfer coefficient $\left(K_{\mathrm{g}}, \mathrm{m} \mathrm{d}^{-1}\right)$ is related to individual mass transfer coefficients for the liquid and gas films, $k_{\mathrm{w}}$ and $k_{\mathrm{g}}$, as follows:

$1 / K_{\mathrm{g}}=\left(1 / k_{\mathrm{g}}\right)+\left(H / R T k_{\mathrm{w}}\right)$. 
Obtaining an accurate estimate of mass transfer coefficients is one of the most difficult problems in gas exchange. This difficulty arises because gas transfer is a function not only of wind speed but turbulence at the air-water interface, boundary layer stability, temperature, the presence of surfactants, and surface conditions such as breaking waves and bubble injection (Jahne et al., 1987; Wanninkhof, 1992; Erickson, 1987). Some processes such as wave breaking, which might indicate strong turbulence, may actually inhibit certain mechanisms that control air-water gas exchange (Erickson, 1987). Due to these factors, field and laboratory data often show large discrepancies. Generally, laboratory experiments tend to overestimate gas exchange rates that occur in natural environments (Schwarzenbach et al., 1993; Mackay and Yeun, 1983). It has been shown that natural organic materials can coat the air-water interface of natural waters and inhibit gas transfer. This inhibiting effect has also been shown in laboratory experiments (Jahne et al., 1987; Asher and Pankow, 1991).

Mass transfer coefficients of water vapor, oxygen $\left(\mathrm{O}_{2}\right)$ and carbon dioxide $\left(\mathrm{CO}_{2}\right)$ have been related to wind speed by many researchers (Schwarzenbach et al., 1993; Wanninkhof, 1992; Mackay and Yeun, 1983; Thibodeaux, 1979). $\mathrm{O}_{2}$ and $\mathrm{CO}_{2}$ are commonly used as reference substances to measure $k_{\mathrm{w}}$ since their gas exchange depends only on liquid phase resistance. Water vapor is usually used to measure $k_{\mathrm{g}}$ because its transfer is controlled by the gas phase.

Thibodeaux (1979) provided an empirical equation for the calculation of $k_{\left.\mathrm{g}_{(} \mathrm{H}_{2} \mathrm{O}\right)}$ based on water vapor evaporation measurements. The equation includes both natural and forced evaporation:

$$
\begin{aligned}
k_{\mathrm{g}\left(\mathrm{H}_{2} \mathrm{O}\right)}\left(\mathrm{cm} \mathrm{s}^{-1}\right) & =k_{\mathrm{gn}}+k_{\mathrm{gf}} \\
& =\left[\left(0.14 G \mathrm{r}_{\mathrm{B} 1}^{1 / 3}+0.664 R e^{0.5}\right) D_{\mathrm{a}} S c_{\mathrm{a}}^{1 / 3} / L\right.
\end{aligned}
$$

for laminar flow $\left(R e \leqslant 10^{5}\right)$, and

$$
\begin{aligned}
k_{\mathrm{g}\left(\mathrm{H}_{2} \mathrm{O}\right)}\left(\mathrm{cm} \mathrm{s}^{-1}\right) & =k_{\mathrm{gn}}+k_{\mathrm{gf}} \\
& =\left[\left(0.14 G \mathrm{r}_{\mathrm{B} 1}^{1 / 3}+0.0364 R e^{0.8}\right) D_{\mathrm{a}} S c_{\mathrm{a}}^{1 / 3}\right] / L
\end{aligned}
$$

for turbulent flow $\left(R e \geqslant 10^{5}\right)$

where $G r_{\mathrm{B} 1}=\left[g \varsigma_{\mathrm{B} 1} L^{3}\left(y_{\mathrm{Bi}}-y_{\mathrm{B}}\right)\right] / v^{2}$ is the Grashoff number, $S c_{\mathrm{a}}=v / D_{\mathrm{a}}$ is the Schmidt number, $R e=u_{10} \mathrm{~L} / \mathrm{v}$ is the Reynolds number, $\varsigma_{\mathrm{B} 1}=-1 /\left[y_{\mathrm{Bi}}+M_{1} /\right.$ $\left.\left(M_{\mathrm{B}}-M_{1}\right)\right]$ is the concentration coefficient of volume expansion (i, interface), $M_{\mathrm{B}}$ and $M_{1}$ are the molecular weight of water vapor and air; $L(\mathrm{~cm})$ is the length of deposition surface; $u_{10}\left(\mathrm{~m} \mathrm{~s}^{-1}\right)$ is the wind speed at $10 \mathrm{~m}$; $g\left(\mathrm{~cm} \mathrm{~s}^{-2}\right)$ is the gravitational acceleration; $y_{\mathrm{B}}$ is the water vapor concentration; $v\left(\mathrm{~cm}^{2} \mathrm{~s}^{-1}\right)$ is the kinematic viscosity of air; $D_{\mathrm{a}}\left(\mathrm{cm}^{2} \mathrm{~s}^{-1}\right)$ is the diffusivity of water vapor in air; and $\mathrm{f}, \mathrm{n}$, and $\mathrm{B}$ are subscripts denoting forced evaporation, natural evaporation, and water vapor respectively.

Mackay and Yeun (1983) developed a similar model for $k_{\mathrm{w}}$ by measuring the volatilization rates of 11 organic compounds in a wind-wave tank. $k_{\mathrm{w}}$ values of organic compounds were adjusted for $\mathrm{O}_{2}$ and the following equation was developed:

$$
\begin{aligned}
k_{\mathrm{w}\left(\mathrm{O}_{2}\right)}\left(\mathrm{cm} \mathrm{s}^{-1}\right)= & 1 \times 10^{-4}+1.75 \times 10^{-4} \\
& \times\left(6.1+0.63 u_{10}\right)^{0.5} \mathrm{u}_{10} .
\end{aligned}
$$

Since, according to the two-film model, mass transfer is limited by the rate of molecular diffusion through thin films of air and water on either side of the surface, mass transfer coefficients for water vapor and oxygen can be adjusted for PAHs using their diffusivities in air and water. Eqs. (6) (Atlas et al., 1982) and (7) (Schwarzenbach et al., 1993) have been recommended to adjust individual mass transfer coefficients:

$$
\begin{aligned}
& k_{\mathrm{g}(\mathrm{PAH})}\left(\mathrm{cm} \mathrm{s}^{-1}\right)=k_{\mathrm{g}\left(\mathrm{H}_{2} \mathrm{O}\right)}\left[D_{\mathrm{a}(\mathrm{PAH})} / D_{\mathrm{a}\left(\mathrm{H}_{2} \mathrm{O}\right)}\right]^{0.61}, \\
& k_{\mathrm{w}(\mathrm{PAH})}\left(\mathrm{cm} \mathrm{s}^{-1}\right)=k_{\mathrm{w}\left(\mathrm{O}_{2}\right)}\left[D_{\mathrm{w}(\mathrm{PAH})} / D_{\mathrm{w}\left(\mathrm{O}_{2}\right)}^{0.5},\right.
\end{aligned}
$$

where $D_{\mathrm{a}}$ and $D_{\mathrm{w}}\left(\mathrm{cm}^{2} \mathrm{~s}^{-1}\right)$ are the diffusivities in air and water, respectively.

The objective of this study was to evaluate the collection properties of the WSS for gas-phase polycyclic aromatic hydrocarbons (PAHs). To meet this objective gas-phase fluxes of PAHs were measured with the WSS. Oxygen transfer experiments were also performed to determine the relationship between wind speed and liquid-phase individual mass transfer coefficient. In this study gas-phase overall mass transfer coefficients for PAHs to the WSS, calculated from concurrent gas-phase flux and ambient concentration measurements, were compared to the predictions of the model developed based on gas transfer experiments performed with the WSS and to previously published models.

\section{Experimental}

\subsection{Sampling and analysis}

The sampling and analytical methods are described in detail elsewhere (Odabasi, 1998; Odabasi et al., 1999a, b) and will only be briefly described here. Twelve dry deposition and ambient air samples were collected between June and October 1995 on the roof of a four-story building (12-m height) located on the campus of Illinois Institute of Technology during the daytime when there was no precipitation. Average sampling time was 6 days $(6 \times 12 \mathrm{~h})$ for dry deposition samples and $24 \mathrm{~h}(2 \times 12 \mathrm{~h})$ for air samples (3/dry deposition sample). The average sampling volume for air samples was about $140 \mathrm{~m}^{3}$. 
Meteorological data were obtained from a meteorological tower located on the top of the same building. However, when the instruments on the tower malfunctioned, meteorological data was obtained from Mid-way Airport or from the meteorological station located on the lakefront. Meteorological parameters in Table 1 were obtained by averaging the hourly values over the sampling periods, with the exception of water temperatures which were calculated based on the hourly measurements (5 each sampling day) of the water temperature in the WSS.

Total (particulate + gas) PAH fluxes were measured using an aerodynamically smooth circular water collection surface while the particulate-phase dry deposition flux was measured using smooth, greased plates with a sharp leading edge (Odabasi, 1998; Odabasi et al., 1999a). Two water surface samplers, one containing a filter holder and a resin column in the water recirculation line (WSS1) and one containing only a resin column in the water recirculation line (WSS2) were used during sampling. The water surface holder has an airfoil shape with a sharp leading edge to minimize airflow disruptions. The water surface plate $(39.4 \mathrm{~cm}$ diameter, $0.65 \mathrm{~cm}$ depth) was placed inside the holder at a height, which allows the water on the plate to be at the same level as the top of the water surface holder. The WSS has a water replenishing system to maintain a constant water level and keep the water retention time on the surface as short as possible (2-4 min) to prevent losses of deposited PAHs. Water enters the water surface plate from its center and overflows from the triangular weirs located at the sides. The water then goes through a filter (WSS1) which captures particles and a resin (XAD-2) column which adsorbs the PAHs before completing a cycle (Odabasi et al., 1999a).

Air samples were collected concurrently using a modified high-volume sampler Model PS-1 (General Metal
Works Inc.). Particles were collected on 11-cm diameter glass fiber filters. The gas-phase compounds were collected in a modified cartridge containing XAD-2 resin placed between layers of polyurethane foam (PUF). Collected samples were analyzed for PAHs using a HP GC/MS system consisting of a HP Model 5890 Series II gas chromatograph and a HP Model 5971A mass selective detector (MSD).

\subsection{Oxygen transfer experiments}

Field experiments were conducted to measure waterphase mass transfer coefficients for oxygen, $k_{\mathrm{w}\left(\mathrm{O}_{2}\right)}$ with the WSS. $k_{\mathrm{w}\left(\mathrm{O}_{2}\right)}$ was measured at different wind speeds to determine the correlation between $k_{\mathrm{w}\left(\mathrm{O}_{2}\right)}$ and wind speed. In these experiments, deionized water with its oxygen content initially reduced to $\sim 0.5 \mathrm{mgl}^{-1}$ by purging nitrogen through it was used. This water was circulated to the water surface plate and dissolved oxygen concentration and water temperature were measured and recorded at 1-min intervals. Dissolved oxygen concentration was measured using an oxygen meter equipped with a membrane electrode. Wind speed was also recorded concurrently at 10-s intervals. This experiment was repeated 13 times. Three of these experiments were conducted after covering the WSS to determine the rate of $\mathrm{O}_{2}$ transfer at zero wind speed.

Individual liquid-phase mass transfer coefficients of oxygen from the $\mathrm{O}_{2}$ transfer experiments were calculated from the absorption coefficient $\left(K_{\mathrm{abs}}, \mathrm{s}^{-1}\right)$, water volume in the WSS $\left(V, \mathrm{~cm}^{3}\right)$ and surface area of the sampler $(A$, $\mathrm{cm}^{2}$ ):

$$
\begin{aligned}
& k_{\mathrm{w}\left(\mathrm{O}_{2}\right)}=(V / A) K_{\mathrm{abs}}, \\
& K_{\mathrm{abs}}=\ln \left[\left(c_{\mathrm{s}}-c\right) /\left(c_{\mathrm{s}}-c_{\mathrm{o}}\right)\right] / \mathrm{t},
\end{aligned}
$$

Table 1

\begin{tabular}{|c|c|c|c|c|c|}
\hline $\begin{array}{l}\text { Sample } \\
\text { No. }\end{array}$ & Date & $\begin{array}{l}\text { Wind speed } \\
\left(\mathrm{m} \mathrm{s}^{-1}\right)\end{array}$ & $\begin{array}{l}\text { Air temp. } \\
\left({ }^{\circ} \mathrm{C}\right)\end{array}$ & $\begin{array}{l}\text { WSS water temp. } \\
\left({ }^{\circ} \mathrm{C}\right)\end{array}$ & $\mathrm{RH}(\%)$ \\
\hline 1 & 14-19 June & 3.3 & 28.8 & 27.0 & 49.6 \\
\hline 2 & 29 June-6 July & 4.2 & 23.7 & 21.9 & 53.6 \\
\hline 3 & $8-13$ July & 3.4 & 26.9 & 25.2 & 57.4 \\
\hline 4 & 14-21 July & 4.2 & 30.1 & 28.4 & 53.6 \\
\hline 5 & 25-30 July & 3.3 & 29.1 & 25.5 & 64.3 \\
\hline 6 & 05-12 August & 3.3 & 29.1 & 27.3 & 67.0 \\
\hline 7 & 15-23 August & 3.2 & 27.3 & 25.5 & 62.9 \\
\hline 8 & 24-31 August & 3.3 & 27.7 & 26.4 & 68.2 \\
\hline 9 & 6-14 September & 4.1 & 19.3 & 17.4 & 57.1 \\
\hline 10 & 15-25 September & 3.9 & 15.8 & 14.6 & 53.9 \\
\hline 11 & 4-13 October & 3.7 & 20.6 & 19.3 & 47.6 \\
\hline 12 & 15-23 October & 5.2 & 14.8 & 13.8 & 44.5 \\
\hline
\end{tabular}

Summary of meteorological data ${ }^{a}$

${ }^{a}$ Wind speed, temperatures and relative humidity were averaged over the sampling period. 
where $c_{\mathrm{s}}$ is the saturation concentration of dissolved $\mathrm{O}_{2}\left(\mathrm{mgl}^{-1}\right)$ at temperature $T\left({ }^{\circ} \mathrm{C}\right), c$ is the dissolved $\mathrm{O}_{2}$ concentration at time $t(\mathrm{~s})$, and $c_{\mathrm{o}}$ is the initial dissolved $\mathrm{O}_{2}$ concentration. $\ln \left[\left(c_{\mathrm{s}}-c\right) /\left(c_{\mathrm{s}}-c_{\mathrm{o}}\right)\right]$ values were plotted against $t$ for each experiment. $K_{\text {abs }}$ was obtained as the slope of the linear regression line.

\section{Results and discussion}

A schematic representation of the calculation of modeled and experimental PAH gas-phase overall mass transfer coefficients is given in Fig. 1.

\subsection{Models developed from WSS experiments}

Recently, wind speed was empirically correlated to the mass transfer coefficients of several species for which transfer to the WSS is controlled by air side resistance (Shahin and Holsen, 2000). The measured mass transfer coefficients $\left(k_{\mathrm{g}}\right)$ of nitric acid $\left(\mathrm{HNO}_{3}\right)$, water vapor $\left(\mathrm{H}_{2} \mathrm{O}\right)$, sulfur dioxide $\left(\mathrm{SO}_{2}\right)$, and ammonia $\left(\mathrm{NH}_{3}\right)$ gases were divided by the square root of the respective diffusivity and regressed against wind speed $10 \mathrm{~m}$ above the water surface $\left(k_{\mathrm{g}} / D_{\mathrm{a}}^{0.5}\right.$ vs. $\left.u_{10}\right)$ and the following relationship obtained:

$k_{\mathrm{g}}=D_{\mathrm{a}}^{0.5}\left(1.08 u_{10}+0.85\right)$,

where, $k_{\mathrm{g}}$ is the mass transfer coefficient, $\mathrm{cm} \mathrm{s}^{-1}, D_{\mathrm{a}}$ is diffusion coefficient in air, $\mathrm{cm}^{2} \mathrm{~s}^{-1}$, and $u_{10}$ is the wind speed in $\mathrm{m} \mathrm{s}^{-1}$ Statistical analysis at the $95 \%$ confidence level indicated that the linear relationship between the mass transfer coefficient and wind speed is significant. The relationship given in Eq. (10) was developed based on wind speed range $0.8-6.0 \mathrm{~m} \mathrm{~s}^{-1}$.

Fig. 2 compares the $k_{\left.\mathrm{g}_{(} \mathrm{O}\right)}$ values calculated using the WSS model to those calculated using Thibodeaux's model (Eqs. (3) and (4)). $k_{\left.\mathrm{g}_{(} \mathrm{H}_{2} \mathrm{O}\right)}$ values predicted by the WSS model were higher than ones calculated by Thibodeaux's model, particularly at low wind speeds.

Experimental $k_{\mathrm{w}\left(\mathrm{O}_{2}\right)}$ values calculated using Eq. (8) were plotted against wind speed and a second-order curve (Schwarzenbach et al., 1993; Wanninkhof, 1992) was fit through the individual data points (Fig. 3). The following relationship was obtained:

$$
k_{\mathrm{w}\left(\mathrm{O}_{2}\right)}=1.62 \times 10^{-3}+2.23 \times 10^{-4} u_{10}+1.66 \times 10^{-4} u_{10}^{2} .
$$

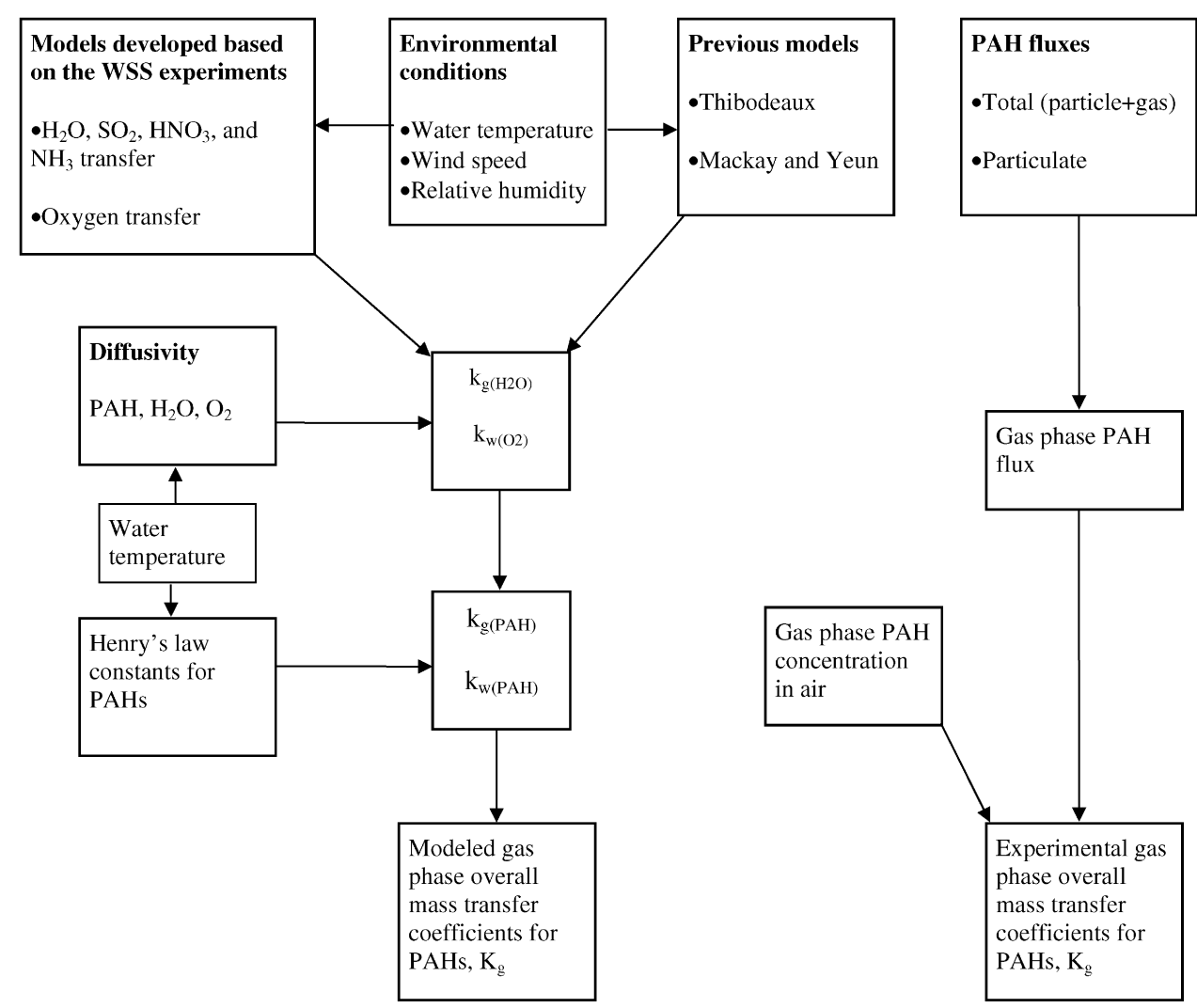

Fig. 1. Schematic description of the calculation of experimental and modeled PAH gas-phase overall mass transfer coefficients. 


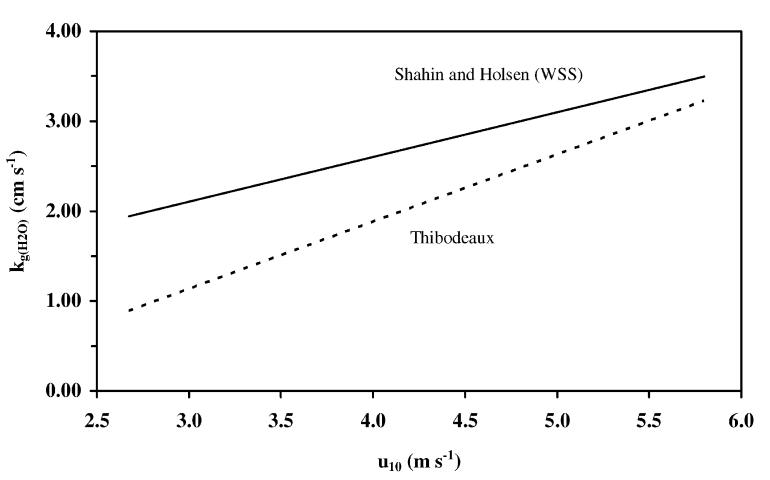

Fig. 2. Variation of $k_{\mathrm{g}_{\left(\mathrm{H}_{2} \mathrm{O}\right)}}$ with wind speed.

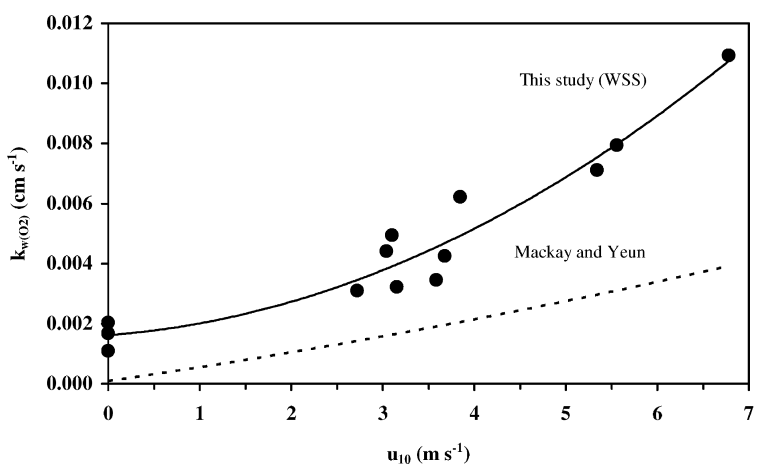

Fig. 3. Variation of $k_{\mathrm{w}\left(\mathrm{O}_{2}\right)}$ with wind speed.

The correlation between $k_{\mathrm{w}\left(\mathrm{O}_{2}\right)}$ and wind speed was good $\left(r^{2}=0.94\right)$. This relationship was developed on wind speed range from 0 to $6.8 \mathrm{~m} \mathrm{~s}^{-1}$. The $k_{\mathrm{w}\left(\mathrm{O}_{2}\right)}$ model developed for the WSS predicts approximately two times larger values than the model of Mackay and Yeun (1983) (Fig. 3).

Individual mass transfer coefficients, $k_{\mathrm{w}\left(\mathrm{O}_{2}\right)}$ and $k_{\mathrm{g}\left(\mathrm{H}_{2} \mathrm{O}\right)}$ calculated using the models described above were adjusted for PAHs using Eqs. (6) and (7). Meteorological parameters (wind speed and temperature) used in the calculations were the average values over the sampling periods. Diffusivities of PAHs in air $\left(D_{\mathrm{a}}\right)$ and water $\left(D_{\mathrm{w}}\right)$ were calculated using the Fuller and Hayduk and Laudie methods (Schwarzenbach et al., 1993; Lyman et al., 1990). These individual mass transfer coefficients $\left(k_{\mathrm{g}}, k_{\mathrm{w}}\right)$ were used to calculate gas-phase overall mass transfer coefficients $\left(K_{\mathrm{g}}\right)$ for the PAHs (Eq. (2)). Henry's law constants for PAHs except for carbazole were taken from a recent experimental study (Bamford et al., 1999). These constants were adjusted for the ambient temperature using the following relationship:

$\ln H=b+m(1 / T)$,
Table 2

Henry's law constants at $25^{\circ} \mathrm{C}, b$ and $m$ values used in Eqs. (12) and (13)

\begin{tabular}{lllll}
\hline PAHs $^{\mathrm{a}}$ & $\mathrm{H}\left(\mathrm{L} \mathrm{atm} \mathrm{mol}^{-1}\right)$ & Ref. $^{\mathrm{b}}$ & $b$ & $m$ \\
\hline ACT & 0.1829 & $(1)$ & 20.3 & -6552 \\
FLN & 0.0968 & $(1)$ & 18.4 & -6178 \\
PHE & 0.0423 & $(1)$ & 16.9 & -5990 \\
ANT & 0.0557 & $(1)$ & 17.1 & -5944 \\
CRB & $1.71 \times 10^{-5}$ & $(2,3)$ & - & -5457 \\
FL & 0.0193 & $(1)$ & 12.6 & -4942 \\
PY & 0.0169 & $(1)$ & 14.2 & -5457 \\
\hline
\end{tabular}

a Acenaphthene (ACT), fluorene (FLN), phenanthrene (PHE), anthracene (ANT), carbazole (CRB), fluoranthene (FL), and pyrene (PY).

b(1): Bamford et al., 1999, (2): Lyman, W.J. et al., 1990, (3): Liang, C. and Pankow, J.F., 1996.

where $b$ is the intercept, $m$ is the slope of $\ln H(T)$ vs. $(1 / T)$ regression line, $T$ is the temperature $(\mathrm{K})$. Table 2 shows the Henry's law constants for PAHs (at $25^{\circ} \mathrm{C}$ ), $b$ and $m$ values used for temperature adjustment.

The following relationship was also used by Hoff et al. (1996) for the temperature adjustment of $H$ :

$H(T)=H\left(T_{\mathrm{r}}\right) / \exp \left[m\left(1 / T_{\mathrm{r}}-1 / T\right)\right]$,

where $T(\mathrm{~K})$ is the temperature of interest, $T_{\mathrm{r}}(\mathrm{K})$ is the reference temperature which $H$ was measured or calculated, $\mathrm{m}$ is the slope of the $\ln H(T)$ vs. $(1 / T)$ regression line. Hoff et al. (1996) used the $m$ value for fluoranthene calculated from experimental data for the temperature adjustment of $H$ values for pyrene and phenanthrene, based on the assumption that these two compounds were similar to fluoranthene.

In this study, since there was no experimental data available for carbazole, $H$ values for this compound were adjusted for different temperatures using Eq. (13) with an $m$ value of -5456 , assuming it was similar to pyrene (Table 2).

\subsection{Experimental gas-phase overall mass transfer coefficients}

Gas-phase PAH fluxes were calculated by subtracting the dry deposition plate fluxes (particulate) from WSS fluxes (particulate + gas). The calculated gas-phase fluxes and results of ambient concentration measurements were reported previously (Odabasi et al., 1999a, b). Possible sampling artifacts for ambient samples (breakthrough of cartridge, adsorption or volatilization from filter) evaluated elsewhere using Junge-Pankow partitioning modeling and quality assurance, quality control requirements (Odabasi, 1998: Odabasi et al., 1999b) and it was concluded that measured concentrations were 
representative of air concentrations. Possible sampling artifacts associated with the WSS and dry deposition plates are discussed in detail elsewhere and will only be briefly discussed here (Odabasi et al., 1999a). Quantities of gas-phase PAHs absorbed by grease were estimated using temperature-adjusted octanol-air partitioning coefficients, the average amount of grease used, and the measured gas-phase ambient concentrations during each sampling period. Estimated quantities absorbed by grease were not significant and measured particulate phase fluxes were not corrected for this artifact (Odabasi et al., 1999a). Shahin et al. (1999) also reported that the amount of deposited PAH due to gas-phase deposition was not significant compared to particle deposition. It was assumed that reactive losses of deposited PAHs from dry deposition plates due to exposure to solar radiation and atmospheric oxidants during sampling were insignificant. Comparison by compound indicated that total fluxes measured with two water surface samplers (WSS1 and WSS2) were statistically the same. Statistical comparisons also indicated that the WSS and dry deposition plates have similar collection properties for particulate dry deposition.

The PAH gas-phase overall mass transfer coefficients $\left(K_{\mathrm{g}}\right)$ calculated from experimental data using Eq. (1) are shown in Fig. 4. In this calculation it was assumed that the PAH concentration in water $\left(C_{\mathrm{w}}\right)$ was zero since the water that was introduced to the surface had passed through the resin column which adsorbed the previously deposited compounds. Measurements made using a back-up column following this initial column indicated that the first column adsorbed essentially all of the deposited PAHs (Odabasi et al., 1999a). The average $K_{\mathrm{g}}$ value for seven PAHs was $0.74 \pm 0.52 \mathrm{~cm} \mathrm{~s}^{-1}$. Tasdemir (1997) used the same apparatus to measure PCB mass transfer coefficients and found a similar average $K_{\mathrm{g}}$ value $\left(0.68 \pm 0.64 \mathrm{~cm} \mathrm{~s}^{-1}\right)$.

Gas-phase fluxes and ambient concentrations were well correlated (Fig. 5). The $r^{2}$ value was 0.73 . The linear relationship between the gas-phase fluxes and ambient concentrations was statistically significant (one-tail

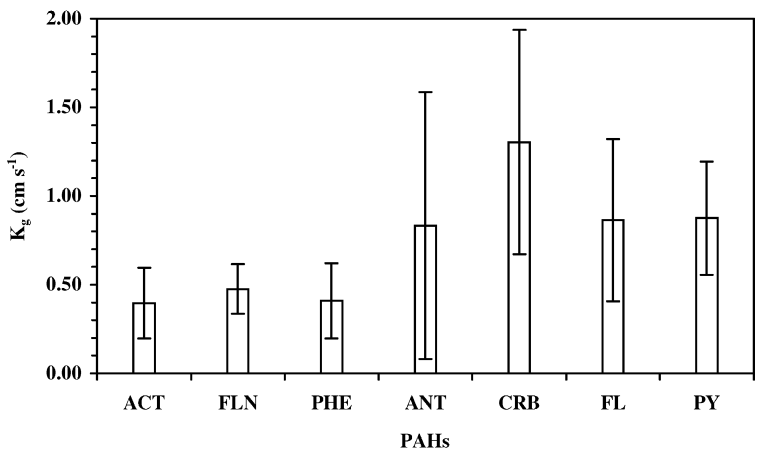

Fig. 4. Gas-phase overall mass transfer coefficients. Error bars represent one standard deviation.
$F$-test, 95\% confidence level). The slope of the linear regression line, $310 \mathrm{~m} \mathrm{~d}^{-1}$ or $0.36 \mathrm{~cm} \mathrm{~s}^{-1}$ is the best-fit gas-phase overall mass transfer coefficient $\left(K_{\mathrm{g}}\right)$. This value agreed well with the average $K_{\mathrm{g}}$ values calculated for individual compounds. The slope of the linear regression line was also statistically significant (one-tail $t$-test, $95 \%$ confidence level).

Comparison between WSS models and experimental results. Experimental and modeled gas-phase overall mass transfer coefficients are compared in Fig. 6. Statistical analysis (one-tail $F$-test, $95 \%$ confidence level) indicated that the linear relationship between the experimental and modeled $K_{\mathrm{g}}$ values calculated using the WSS model is significant. The slope of regression equation in Fig. 6 is statistically equal to one and the intercept is equal to zero (one-tail $t$-test, 95\% confidence level). These results indicate that the experimental $K_{\mathrm{g}}$ is the same as the predicted $K_{\mathrm{g}}$ using the WSS models.

Comparison between Thibodeaux and Mackay and Yeun models and experimental results. Gas-phase overall mass transfer coefficients for PAHs were also calculated using individual water vapor and oxygen mass transfer coefficients calculated from Thibodeaux (1979) and Mackay and Yeun (1983) models (Eqs. (3)-(5)). According to Thibodeaux (1979) $k_{\mathrm{g}\left(\mathrm{H}_{2} \mathrm{O}\right)}$ is a function of temperature, wind speed, relative humidity and length of the deposition surface (Eqs. (3) and (4)). Since the deposition surface of the WSS is circular, the length of the deposition surface is variable. Therefore, the surface area of the WSS was divided into nine segments parallel to wind direction (seven having $5 \mathrm{~cm}$, two having $2 \mathrm{~cm}$ width). $k_{\left.\mathrm{g}_{\left(\mathrm{H}_{2}\right.} \mathrm{O}\right)}$ values for each segment were calculated based on its length. An individual mass transfer coefficient which represents the total deposition surface was calculated as the area weighted average of the $\left.k_{\mathrm{g}_{(} \mathrm{O}} \mathrm{O}\right)$ values of all segments ( $\mathrm{Yi}$ et al., 1997a):

Area weighted average $k_{\mathrm{g}\left(\mathrm{H}_{2} \mathrm{O}\right)}=\left(\sum k_{\mathrm{g}\left(\mathrm{H}_{2} \mathrm{O}\right) i} A_{i}\right) / \sum A_{i}$,

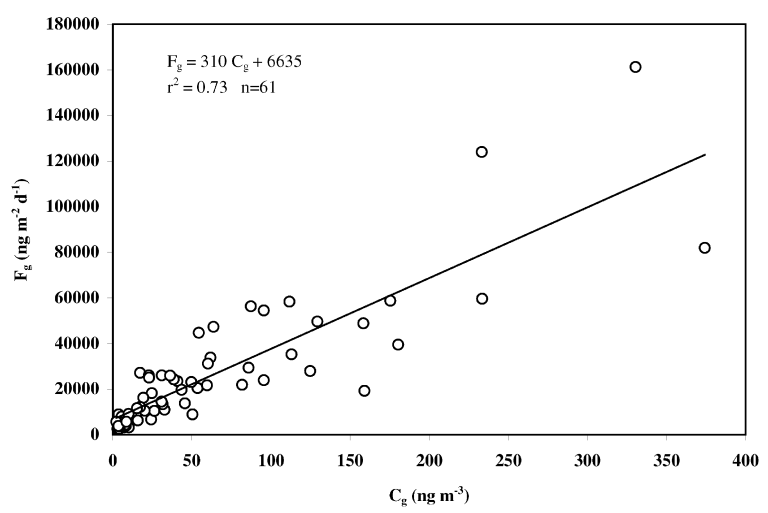

Fig. 5. Relationship between ambient gas-phase PAH concentration and gas-phase PAH flux. 


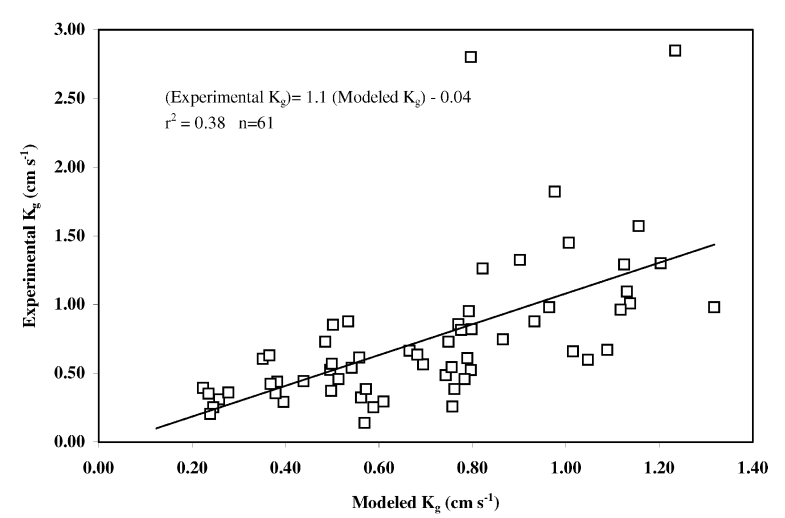

Fig. 6. Comparison of the experimental and predicted $K_{\mathrm{g}}$ values calculated using the WSS model.

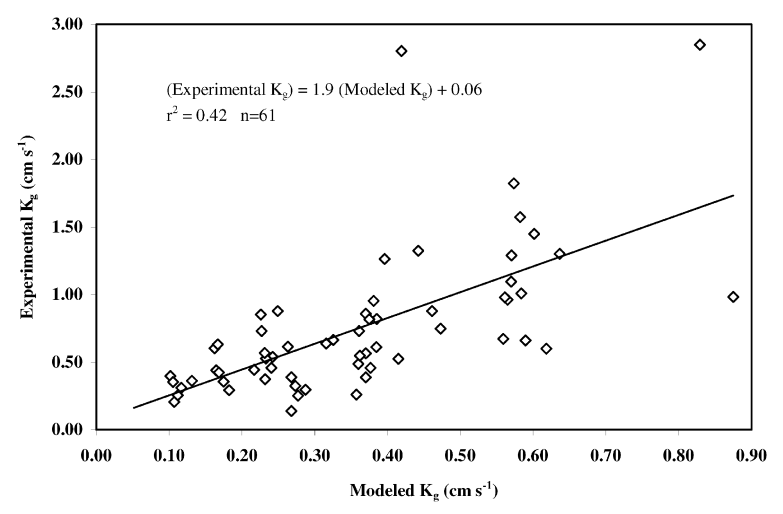

Fig. 7. Comparison of the experimental and predicted $K_{\mathrm{g}}$ values calculated using Thibodeaux's $\left(k_{\mathrm{g}}\right)$ and Mackay and Yeun's model $\left(k_{\mathrm{w}}\right)$.

where $i$ is the segment number, $A_{i}$ and $k_{\mathrm{g}\left(\mathrm{H}_{2} \mathrm{O}\right) i}$ are the area and individual mass transfer coefficient of segment $i$, respectively.

The Reynolds number in Eqs. (3) and (4) under the experimental conditions in this study ranged from 34000 $\left(<10^{5}\right.$, laminar flow) to $140000\left(>10^{5}\right.$, turbulent flow).

The relationship between the experimental and modeled $K_{\mathrm{g}}$ values predicted using the Thibodeaux $\left(k_{\mathrm{g}}\right)$ and Mackay and Yeun model $\left(k_{\mathrm{w}}\right)$ is shown in Fig. 7. The correlation between the experimental and modeled $K_{\mathrm{g}}$ values is statistically significant (one-tail $F$-test, $95 \%$ confidence level). The intercept of linear regression in Fig. 7 is statistically equal to zero (one-tail $t$-test, $95 \%$ confidence level). The slope of regression equation is 1.9 indicating that this model underestimated the experimental $K_{\mathrm{g}}$ values.

This underestimation is the result of underestimating both $k_{\mathrm{w}}$ and $k_{\mathrm{g}}$. Underestimated individual mass transfer coefficients give higher air and water side resistances, $\left(1 / k_{\mathrm{g}}\right)$ and $\left(H / R T k_{\mathrm{w}}\right)$ which causes lower estimated
$K_{\mathrm{g}}$ values (Eq. (2)) and consequently experimental to modeled ratios greater than one. Compounds with relatively high Henry's law constants like acenaphthene have significant water-phase resistance $(>75 \%)$ while there is no significant water phase resistance $(0.1 \%<)$ for compounds with low Henry's law constants like carbazole. The experimental to modeled $K_{\mathrm{g}}$ ratios for most of the compounds were about 2.0, indicating that underestimation by both previously published models (for $k_{\mathrm{w}}$ and $k_{\mathrm{g}}$ ) was important as shown in Figs. 2 and 3.

Yi et al. (1997b) also used the model proposed by Thibodeaux (1979) to predict the gas-phase overall mass transfer coefficients for sulfur dioxide $\left(\mathrm{SO}_{2}\right)\left(\mathrm{SO}_{2}\right.$ transfer to the WSS is controlled by air side resistance). Thibodeaux's model also underestimated $(\sim 2$ times) the $K_{\mathrm{g}}$ values for $\mathrm{SO}_{2}$ determined from direct measurements with the WSS.

The models proposed by Thibodeaux (1979) and Mackay and Yeun (1983) were developed based on field or laboratory experiments, and significantly underpredict gas exchange with the WSS. There are several factors which influence mass transfer coefficients that may be responsible for this including the effect of wind speed, boundary layer stability, temperature, surface contamination, and surface conditions such as breaking waves (Schwarzenbach et al., 1993, Mackay and Yeun, 1983). Mackay and Yeun (1983) reported that drag coefficients calculated in their wind tunnel experiments were higher than those encountered environmentally. They suggested that since the flow characteristics are not fully developed during short fetches, airflow exerts a greater force on the water in the laboratory. This result is supported by wind tunnel experiments with a deposition plate having a sharp leading edge. In these experiments it was reported that turbulence was greatest at the leading edge and decreased with the distance from the edge (McCready, 1986). This increased turbulence near the leading edge was recently investigated by using one WSS with a $6 \mathrm{~cm}$ leading edge (the same as the WSS used in this study) and, one having a $60 \mathrm{~cm}$ leading edge (Hsu, 1997). Visually it was obvious that the WSS with a longer leading edge had smoother water with less waves. This decrease in turbulence translated to nitrate, sulfate and, water evaporation fluxes which were $10-15 \%$ lower than those measured with the WSS having a shorter leading edge.

Constantly recycling the water to the water surface plate may also effect the gas transfer to the WSS. The water on the surface is shallow $(0.65 \mathrm{~cm})$ and constant addition and loss of water may decrease the stability of water side laminar sublayer increasing $k_{\mathrm{w}\left(\mathrm{O}_{2}\right)}$.

\section{Acknowledgements}

The support of Yucel Tasdemir (Uludag University, Turkey) and Nedim Vardar (Balikesir University, 
Turkey) in field sampling and laboratory analysis is greatly appreciated. We would like to thank Warawut Suadee for his assistance in air sampling; Kenneth E. Noll and Nasrin R. Khalili (Illinois Institute of Technology) for their support during the study.

\section{References}

Asher, W., Pankow, J.F., 1991. Prediction of gas/water mass transport coefficients by a surface renewal model. Environmental Science and Technology 25, 1294-1300.

Atlas, E., Foster, R., Glam, C.S., 1982. Air-sea exchange of high molecular weight organic pollutants: laboratory studies. Environmental Science and Technology 16, 283-286.

Baker, J.E., Eisenreich, S.J., 1990. Concentrations and fluxes of polycyclic aromatic hydrocarbons and polychlorinated biphenyls across the air-water interface of Lake Superior. Environmental Science and Technology 24, 342-352.

Bamford, H.A., Poster, D.L., Baker, J.E., 1999. Temperature dependence of Henry's law constants of thirteen PAHs between $4^{\circ} \mathrm{C}$ and $31^{\circ} \mathrm{C}$. Environmental Toxicology Chemistry 18 (9), 1905-1912.

Erickson III, D.J., 1987. A stability dependent theory for air-sea gas exchange. Journal of Geophysical Research 98, 8471-8488.

Gustafson, K.E., Dickhut, R.M., 1997. Gaseous exchange of polycyclic aromatic hydrocarbons across the air-water interface of Southern Chesapeake Bay. Environmental Science and Technology 31, 1623-1629.

Hoff, R.M., Strachan, W.M.J., Sweet, C.W., Chan, C.H., Shackleton, M., Bidleman, T.F., Brice, K.A., Burniston, D.A., Cussion, S., Gatz, D.F., Harlin, K., Schroeder, W.H., 1996. Atmospheric deposition of toxic chemicals to the Great Lakes: a review of data through 1994. Atmospheric Environment 30, 3505-3527.

Hornbuckle, K.C., Jeremiason, J.D., Sweet, C.W., Eisenreich, S.J., 1994. Seasonal variations in air-water exchange of polychlorinated biphenyls in Lake Superior. Environmental Science and Technology 28, 1491-1501.

Hsu, Y.-K., 1997. MS Thesis, Illinois Institute of Technology, Chicago, IL.

Jahne, B., Münnich, K.O., Bössinger, R., Dutzi, A., Huber, W., Libner, P., 1987. On the parameters influencing air-water gas exchange. Journal of Geophysical Research 92, 1937-1949.

Liang, C., Pankow, J.F., 1996. Gas/particle partitioning of organic compounds to environmental tobacco smoke: partitioning coefficient measurements by desorption and comparison to urban particulate material. Environmental Science and Technology 30, 2800-2805.

Lyman, W.J., Reehl, W.F., Rosenblatt, D.H., 1990. Handbook of Chemical Property Estimation Methods: Environmental Behavior of Organic Compounds. American Chemical Society, Washington DC.
Mackay, D., Yeun, A.T.K., 1983. Mass transfer coefficient correlations for volatilization of organic solutes from water. Environmental Science and Technology 17, 211-217.

McConnell, L.L., Nelson, E., Rice, C.P., Baker, J.E., Johnson, W.E., Harman, J.A., Bialek, K., 1997. Chlorpyrifos in the air and surface water of Chesapeake Bay: predictions of atmospheric deposition fluxes. Environmental Science and Technology $31,1390-1398$.

McCready, D.I., 1986. Wind tunnel modeling of small particle deposition. Aerosol Science and Technology 5, 301-312.

McVeety, B.D., Hites, R.A., 1988. Atmospheric deposition of polycyclic aromatic hydrocarbons to water surfaces: a mass balance approach. Atmospheric Environment 22, 511-536.

Odabasi, M., 1998. The measurement of PAH dry deposition and air-water exchange with the water surface sampler. Ph.D. Thesis, Illinois Institute of Technology, Chicago, IL.

Odabasi, M., Sofuoglu, A., Vardar, N., Tasdemir, Y., Holsen, T.M., 1999a. Measurement of dry deposition and air-water exchange of polycyclic aromatic hydrocarbons with the water surface sampler. Environmental Science and Techno$\operatorname{logy} 33,426-434$.

Odabasi, M., Vardar, N., Tasdemir, Y., Sofuoglu, A., Holsen, T.M., 1999b. Polycyclic aromatic hydrocarbons in Chicago air. The Science of the Total Environment 227, 57-67.

Pirrone, N., Keeler, G.J., Holsen, T.M., 1995. Dry deposition of semivolatile organic compounds to Lake Michigan. Environmental Science and Technology 29, 2123-2132.

Schwarzenbach, R.P., Gschwend, P.M., Imboden, D.M., 1993. Environmental Organic Chemistry, Wiley Interscience, New York.

Shahin, U., Holsen, T.M., 2000. Dry deposition of reduced and reactive nitrogen: a comparison to modeled results. Environmental Science and Technology, submitted for publication.

Shahin, U.M., Li, H.-W., Holsen, T.M., 1999. Dry deposition of gas phase polycyclic aromatic hydrocarbons to greased surrogate surfaces. Aerosol Science and Technology 31 (6), 446-455.

Tasdemir, Y., 1997. Modification and evaluation of a water surface sampler to investigate the dry deposition and air-water exchange of polychlorinated biphenyls (PCBs). Ph.D. Thesis, Illinois Institute of Technology, Chicago, IL.

Thibodeaux, L.J., 1979. Chemodynamics: Environmental Movement of Chemical in Air, Water, and Soil. Wiley, New York.

Wanninkhof, R., 1992. Relationship between wind speed and gas exchange over the ocean. Journal of Geophysical Research 97, 7373-7382.

Yi, S.-M., Holsen, T.M., Noll, K.E., 1997a. Comparison of dry deposition predicted from models and measured with a water surface sampler. Environmental Science and Technology 31, 272-278.

Yi, S.-M., Holsen, T.M., Zhu, X., Noll, K.E., 1997b. Sulfate dry deposition measured with a water surface sampler: a comparison to modeled results. Journal of Geophysical Research 102, 19695-19705. 